\title{
The impact of a monitoring scheme on engagement in an online course
}

\author{
Gráinne Burke, Ciarán Mac an BhaIRD* and AnN O'SheA \\ Department of Mathematics and Statistics, National University of Ireland Maynooth, \\ Maynooth, Co. Kildare, Ireland \\ *Email: ciaranmacanbhaird@gmail.com
}

[Submitted October 2011; accepted March 2012]

\begin{abstract}
In the National University of Ireland Maynooth, in-coming first-year mathematics students are given a diagnostic test. The purpose of this test is to measure their basic knowledge and manipulation skills in mathematics. Those who fail this test are deemed at risk of failing their mathematics modules and are enrolled in a supplementary online mathematics proficiency course. In this article, we give a brief overview of the development of this course. We focus on the issue of student engagement with the course and the steps we have taken to address their levels of engagement; in particular, we have monitored student activity in the online course and contacted students whose engagement levels were low. We also present an analysis of the impact of this course on students' overall grades.
\end{abstract}

\section{Introduction}

The Department of Mathematics and Statistics at the National University of Ireland Maynooth (NUIM) administers a diagnostic test in the first week of the academic year to all first-year students taking a mathematics module. The students who take the test are often categorized as service mathematics students as they are usually taking mathematics modules as part of a science or finance degree and they are not pure mathematics students. This test covers very basic mathematical material and has been developed over the past 25 years. It is available to fellow academics upon request. The test consists of 20 multiple choice questions; three marks are awarded for a correct answer and one mark is deducted for an incorrect answer. Students who receive less than 21 out of 60 are deemed to have failed this test and are categorized as at risk.

Over the years, various initiatives have been used to support these students. These initiatives include extra weekly tutorials on foundational material and laboratory sessions using a software package called CALMAT. Normally the level of student engagement with this support was quite low. In an effort to increase student participation, in 2008 the last author developed an online mathematics proficiency course to provide this extra support.

The course runs on Moodle (the Virtual Learning Environment used at NUIM), and consists of 18 segments. Each segment contains links to video tutorials and notes from the Mathtutor website (http://www.mathtutor.ac.uk, accessed 15 January 2012), along with a quiz designed by the last author, which gives students an opportunity to test if they have mastered the material. Students are given three 
opportunities to take each quiz. The course covers topics in basic algebra (eight sections), trigonometry (four sections), functions (two sections) and some additional sections on material related to series. There is also a weekly workshop, which concentrates on a topic from the module.

Students who fail the diagnostic test are automatically enrolled for this online course, but other students can also enrol. The department considers the material covered in this course to be prerequisite knowledge for first-year modules; however, it is a non-compulsory zero credit course and so does not contribute to students' final grade. In 2009/10, 311 science and 159 arts students took the test; 224 students failed the proficiency test and were enrolled on the course. However, participation levels were quite low and the course had only 3513 hits in total; this compares unfavourably with 6680 hits from 262 students in 2008/9. In 2010/11, it was decided to introduce a monitoring system, whereby participation was tracked and contact was made with students who were not engaging with the course.

In this article, we will describe the level of monitoring that took place, as well as the subsequent action taken and advice given by the student monitor to students who were not engaging appropriately with the online course. We will also compare the data from this academic year (2010/11) with the previous year when there was no monitoring or additional interventions. We show that the monitoring process has led to a statistically significant increase in student engagement with the online course. We also present data that strongly suggest that students who make regular use of the online course can expect a better grade in their mathematics modules than those who do not engage.

\section{Literature review}

The supports described by the authors are very similar in nature to those categorized as proactive supports by Lawson et al. (2006). The research most relevant to this article in this area is contained in Rae \& Samuels (2011). They give a detailed description of various implementations of web-based personalized systems of instructions (WPSIs). In particular, they look at the effectiveness of a supplementary course provided to at risk students at Coventry University. The progression and development of the course over four academic years, 2006-2010, is outlined, and they provide evidence of the positive impact of this course on the module grades of students who engaged, as opposed to students who did not. However, the level of the impact does change depending on the varying cohort of students availing the support on a given year. The authors also mention the issue of incentivizing students to engage with certain parts of the course material.

There are a number of papers that consider students' levels of engagement with mathematics support in general and the benefits of such engagement, e.g. Symonds (2008), Pell and Croft (2008) and Mac an Bhaird et al. (2009). These papers also highlight that it is not always the students in greatest need of support that regularly access it; indeed, Mac an Bhaird et al. (2009) found that a large minority of at risk students did not make use of the help available to them. Lee et al. (2008) found that a student's level of mathematical preparation (in the form of diagnostic test scores and the number of statistics modules taken at A-level) and whether they availed of mathematics support were good predictors of success in university examinations. Golden et al. (2007) report on an initiative where online learning supports were embedded in a module that was otherwise taught in a traditional manner. In particular, computer-based tests were used at regular intervals as part of a continuous assessment system and to give instant feedback to students on their progress. This was complemented by a suite of web-based resources. Golden et al. (2007) found that this method of course delivery can increase both student reflection on and engagement with their studies.

It is well-known that online courses often suffer from higher drop-out rates than traditional courses; a considerable amount of research in this area considers the factors that determine students' level of 
engagement with online courses, e.g. Truluck (2007) and Brett (2004). Though the majority of these papers deal only with compulsory online courses, they raise important issues which could help address engagement issues with non-compulsory courses. For example, Brett (2004) discusses factors such as the levels of Internet access at home; however, these problems may have lessened recently due to improved access to broadband. She also mentions user familiarity with the shared online environment. She states that 'Understanding more about the online and off-line factors that contribute to the online experience is important in order to support effective online learning experiences for a broader range of learners' (p. 83). Truluck (2007) reports that the impersonal nature of online courses can lead to feelings of isolation in students and outlines a mentoring plan used in an online graduate programme at the University of Georgia.

Some research focuses on the impact that interventions can have on student engagement with support and services provided, but we could find no studies that consider supplementary online courses. Anderson and Gates (2003) describe an initiative that involved intervention with first-year students at the University of Mississippi and connected class attendance with student success. Students in 'an intervention group' who had two or more absences from class were contacted and advised on the various support services available at that university. The grade point average (GPA) of these students was compared to similar students in 'a control group' whose absences were noted but they were not contacted. The first group showed a much better rate of success and specifically had a better GPA.

Another study, which used Anderson and Gates (2003) as a template, was carried out in the University of Glasgow (Hume, 2004) and compared two types of intervention with students. Students who missed two tutorials in a row were randomly assigned to two intervention groups: students in the first group received a phone call from the author (a student volunteer); and students in the second group received an e-mail from the author. In both interventions, students were given general advice on how to seek help or support and each group contained 30 students; there was no control group. The study showed that the students who were telephoned were less likely to drop out of the course when compared with those who were e-mailed and that they were receptive to the intervention and advice received. However, there was no significant difference between the grades of the students in each group who completed their course. Richie and Hargrove (2004) carried out a similar study in the University of Mississippi. They carried out telephone interventions on students in an intervention group compared with a control group who received no contact, and they found statistically fewer absences and higher grades in the intervention group.

Woods (2002) considered the effects of instructor-initiated e-mails on student participation and satisfaction with the learning experience. Students on a graduate-level online course were sent personal e-mails by the instructor. However, no significant difference between participation or satisfaction levels of the group of students who were contacted and those who were not was found.

With the exception of Rae and Samuels (2011), the studies presented here deal with compulsory supports, whether they are online courses or traditional tutorials and lectures. It is clear that student engagement is a complex issue; however, we believe that appropriate intervention has a vital role to play in increasing the level and quality of that engagement.

\section{Monitoring scheme}

At the end of the academic year 2009/10, it was decided to try to increase participation in the online proficiency course by introducing a monitoring scheme. We employed an experienced tutor (the first author) to act as a student monitor. Her duties included analysing the course's online usage statistics at strategic points during the year, and contacting students who were not engaging at an appropriate level with the course. 
The results of the diagnostic test were given to students during the second week of the first semester in 2010/11. All students who had failed this test were signed up for the online proficiency course. They were advised that they should complete at least one segment of the course each week. The monitor checked on student activity at the end of October, 4 weeks after the course went live, and sent an e-mail to students who had completed two segments or less. The e-mail reminded the students about the course and pointed out the benefits of participating in it. She checked the usage statistics again 4 weeks later, and sent a similar e-mail to students who had not completed any segments in the month of November. Students who were being contacted for a second time were asked to meet with their mathematics course co-ordinator to discuss their reasons for not participating in the course.

\section{Results}

We will consider the impact of this monitoring scheme on student engagement with the online proficiency course by comparing usage statistics from the year 2009/10 with the year 2010/11. We will also investigate the influence of participation in the course on the students' final mathematics module grades.

\subsection{Effect of monitoring scheme on participation}

In 2010/11, 540 students sat the proficiency test and 200 students who failed the proficiency test were enrolled in the proficiency course; 224 were enrolled in 2009/10. The number of student hits for the course increased from 3513 in 2009/10 to 23,987 hits in 2010/11. Since we are interested in increasing levels of participation, we will concentrate on the behaviour of students who were contacted by the monitor in 2010/11 or who would have been contacted in the previous year (if a monitoring scheme had been in place then). In 2010/11, 154 students received an e-mail in October and 107 received an e-mail in November. Of these 107 students, 18 were contacted for the first time. If the scheme had been running in 2009/10, then 125 students would have been contacted in October and 111 in November. All 111 of these students would have received a second e-mail.

Figure 1 shows the distributions of the total number of quizzes completed by students who were contacted in October 2010 or would have been contacted in October 2009. It is clear that these distributions are not normal so a Mann-Whitney non-parametric test was used to investigate the difference between the distributions for 2009/10 and 2010/11. We found that they were significantly different $(p<0.001)$.

The distributions of the number of quizzes completed after October were significantly different for the years 2009/10 and 2010/11 ( $p<0.001$ ), with students recording more activity in the second year. In $2009 / 10,89 \%$ of students who had completed two segments of the course or less at the end of October did not take any further quizzes; however, this percentage went down to 47\% in 2010/11. Figure 2 shows the distributions of the number of quizzes subsequently completed by students who received an e-mail in November 2010 or would have received an e-mail in 2009.

Once again the distributions were significantly different $(p<0.001)$. The striking thing in this case is that all students who were not active in the month of November in 2009/10 remained inactive for the remainder of the year, whereas $40 \%$ of students who received an e-mail in November 2010 went on to complete at least one more quiz.

We also considered the distribution of the total number of resources viewed (i.e. the mathtutor materials) in 2010/11 and 2009/10. We found that this distribution for students in 2010/11 who received an e-mail in October 2010 was significantly different from that of the corresponding students 


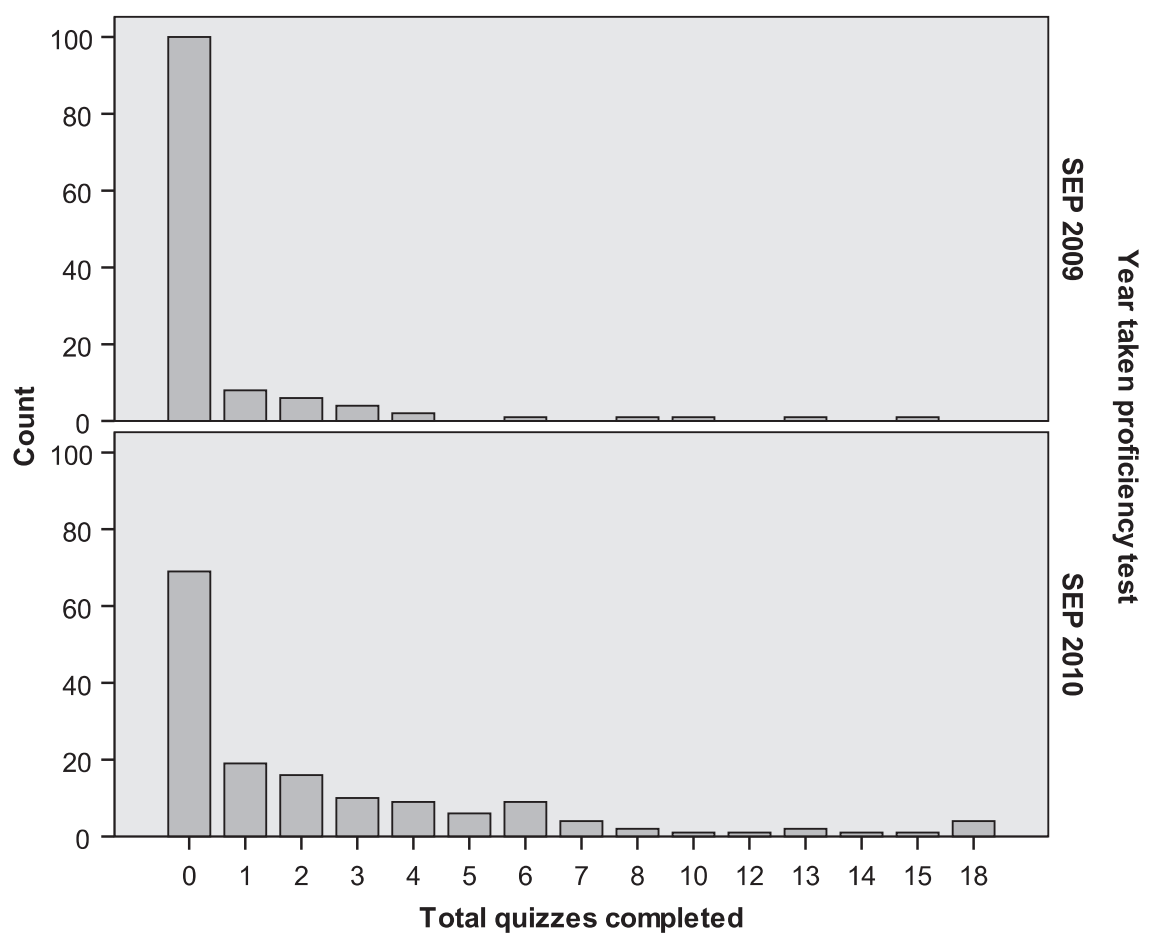

FIG. 1. Comparison of quiz data for students who needed to be contacted in October.

in 2009/10 ( $p=0.43$ ). Similarly, the distribution of resources viewed after November was significantly different for the two cohorts $(p<0.001)$, with the students in 2010/11 viewing more resources.

\subsection{Effect of the online course on grades}

In an effort to determine if participation in the online proficiency course has an effect on mathematics module grades, we carried out a regression analysis for the 2010/11 group. Our dependent variable was the student's end-of-year marks in mathematics (marked out of 1000). Our independent variables were: the student's Leaving Certificate (LC) points for mathematics; the student's diagnostic test score; the total number of quizzes completed by the student; and the total number of resources viewed by the student. (Irish second-level students sit a high-stakes examination called the Leaving Certificate which determines entry to University. Based on this examination, students are awarded points ranging from 5 to 100 for each subject, depending on their grade level.) All of these variables were significantly correlated with the end-of-year marks. The regression model was:

final mathematics mark $=218.035+9.296$ (number of quizzes completed) +3.689 (LC points).

An $R^{2}$-value of 0.201 was obtained for this model. This means that $\sim 20 \%$ of the variation in the final marks of the students can be explained by the variables in the model, i.e. by the number of quizzes completed and the LC points obtained. The student's diagnostic test result and the number of resources viewed were not significant predictors of the final mathematics mark. This may be because of the fact that the LC points and the diagnostic test result were highly correlated with each other as 


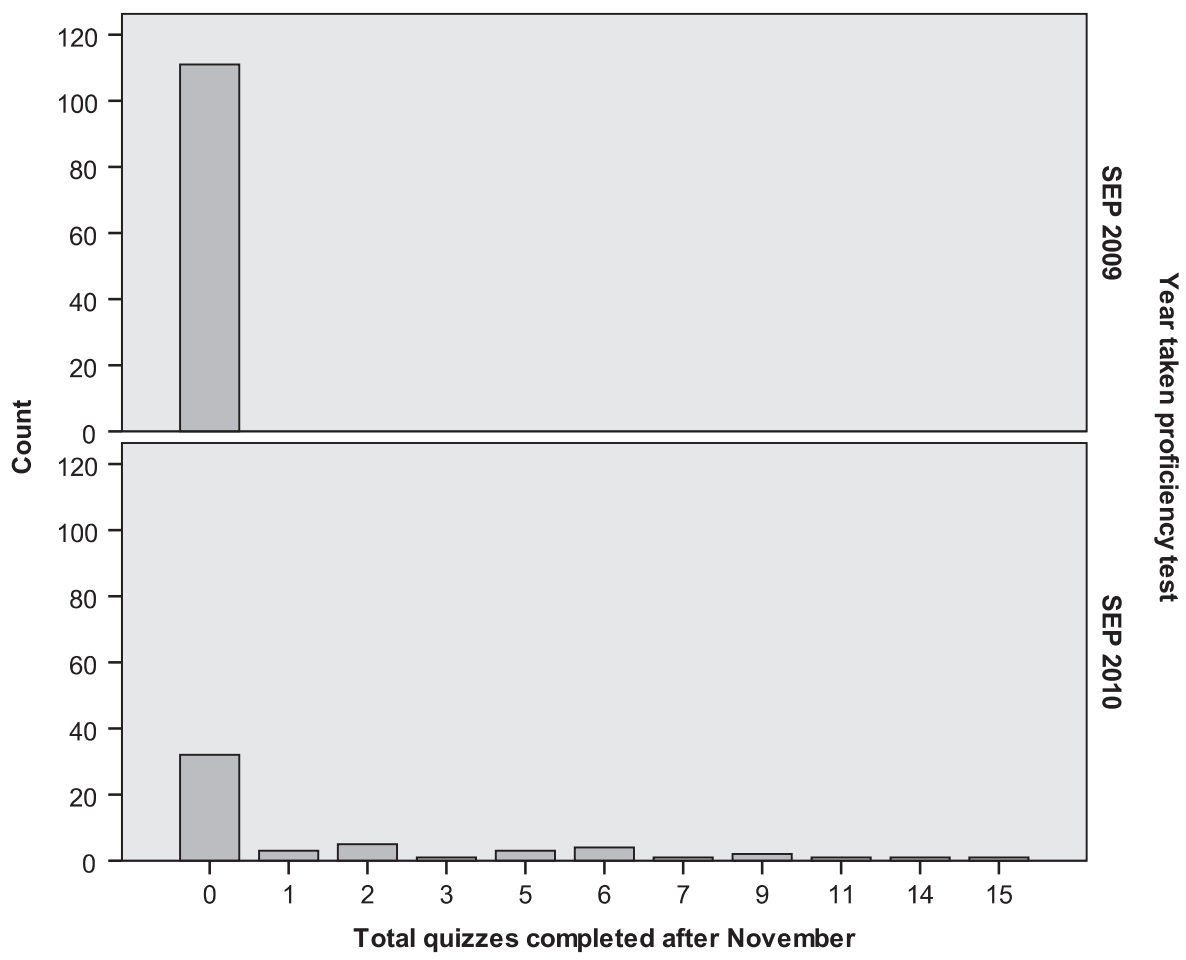

FIG. 2. Comparison of quiz data for students who needed to be contacted in November.

were the number of quizzes completed with the number of resources viewed. The model suggests that the number of quizzes completed by students does have an effect on their final mark; in fact, if LC points are held constant, each quiz adds $\sim 1 \%$ to the student's final subject grade.

\section{Discussion}

The monitoring scheme was introduced in order to increase participation in the online proficiency course. The results reported here show that participation has increased, and this is consistent with the findings of Anderson and Gates (2003) and Hume (2004) on the initial outcomes of their monitoring and intervention schemes. First, we have seen that the overall number of hits by students on the online course has grown dramatically; secondly, we have seen that both the total number of quizzes completed and the total number of resources viewed have significantly increased on 2009/10 levels. Furthermore, the impact of the e-mails sent by the monitor is evident when we consider the higher levels of activity of students contacted in 2010/11 compared with their counterparts in the previous year. In addition, we have found that participation in the online course does have a positive effect on students' grades in mathematics. These findings are similar to those in Rae and Samuels (2011) who report that at risk students who engaged with their supplementary online course out-performed similar students who did not. However, caution must be exercised when considering findings such as these. As outlined in Lee et al. (2008) there are many factors that affect students' performance but which cannot be included in a model such as ours.

Nevertheless, engagement levels are still not as high as we would like. Student feedback seems to suggest that students do not see the relevance of the course to their other mathematics modules. 
This relevance is evident to the mathematics faculty but more effort needs to be employed in directly linking the material on the proficiency course to the material covered in first-year mathematics modules. At the beginning of the next academic year, we will present the results concerning grades of the current study to at risk students in the hope that the findings will encourage them to participate fully in the online course. We also need to consider issues such as students' anxiety and fear when they come to dealing with technology; similar issues are dealt with in Truluck (2007) and Brett (2004), for example.

The initial outcomes of this monitoring scheme are very encouraging, and we aim to increase the level of monitoring and intervention in the coming academic years. We also hope to carry out additional research on other aspects of our online course, for example we would like to investigate students' attitudes towards the online support available. Some work in this area has already been discussed by Golden et al. (2007).

\section{REFERENCES}

Anderson, C. \& Gates, C. (2003) Freshman absence-based intervention at the University of Mississippi. (see http://www.psy.gla.ac.uk/ steve/localed/miss.html) [accessed 15 February 2012].

Brett, C. (2004) Off-line factors contributing to online engagement. Technol. Pedagog. Educ., 13, 83-95.

Golden, K., Stripp, C. \& Lee, S. (2007) Encouraging student use of feedback, reflection and engagement through web-based learning support. MSOR Connect., 7, 7-10.

Hume, J. (2004) Can a single telephone call prevent a student from dropping out? Final year undergraduate project for the Department of Psychology, University of Glasgow. (see http://www.psy.gla.ac.uk/ steve/ localed/docs/hume.pdf) [accessed 15 February 2012].

Lawson, D., Symonds, R. \& Samuels, P. (2006) Proactive interventions in mathematics and statistics support. Proceedings of the CETL-MSOR Conference 2006 (D. Green ed.), pp. 102-107.

Lee, S., Harrison, M., Pell, G. \& Robinson, C. (2008) Predicting performance of first year engineering students and the importance of assessment tools therein. J. High. Educ. Acad. Eng. Subject Acad., 3, 44-51.

Mac an Bhaird, C., Morgan, T. \& O'Shea, A. (2009) The impact of the mathematics support centre on the grades of first year students at the National University of Ireland Maynooth. TEAMAT, 28, 117-122.

Pell, G. \& Croft, T. (2008) Mathematics support—support for all? TEAMAT, 27, 167-173.

Rae, A. \& SAmuels, P. (2011) Web-based personalised system of instruction: an effective approach for diverse cohorts with virtual learning environments? Comp. Educ., 57, 2423-2431.

Richie, S. \& Hargrove, D. (2004) An analysis of the effectiveness of telephone intervention in reducing absences and improving grades of college freshmen. J. Coll. Stud. Retent.: Res. Theory Pract., 6, $395-412$.

Symonds, R. (2008) Evaluating students' engagement with mathematics support. PhD Thesis, Loughborough University, Leicestershire, UK.

Truluck, J. (2007) Establishing a mentoring plan for improving retention in online graduate degree programs. Online J. Dist. Learn. Admin., 10, 1-6.

Woods, R. (2002) How much communication is enough in online courses? Exploring the relationship between frequency of instructor-initiated personal email and learners' perceptions of and participation in online learning. Int. J. Instruct. Media, 29, 377-394.

Gráinne Burke holds a Masters degree in Mathematics and is a senior tutor at the Department of Mathematics and Statistics at NUIM. She also tutors in the Mathematics Support Centre and is in charge of the day to day running of a number of programmes including both the student mentoring and student monitoring schemes. 
Ciarán Mac an Bhaird received his $\mathrm{PhD}$ in Mathematics from NUIM. He has been Manager of the Mathematics Support Centre and a lecturer in the Mathematics and Statistics Department since 2007. $\mathrm{He}$ is a committee member of the Irish Mathematics Learning Support Network and conducts research in Mathematics Education, the History of Mathematics and Algebraic Number Theory.

Ann O'Shea holds a $\mathrm{PhD}$ in Mathematics from the University of Notre Dame, USA. She has been a lecturer in the Mathematics Department at NUI Maynooth since 1992. She is currently the Director of the Mathematics Support Centre. She conducts research in the area of Mathematics Education. 